\title{
Effect of Salt Content on the Evaporation and Cracking of Soil from Heritage Structures
}

\author{
Kai Cui $\mathbb{D}^{1,2}$ Xiaozheng Zhao $\mathbb{D D}^{1,2}$ Mingming $\mathrm{Hu}\left(\mathbb{D},{ }^{3}\right.$ Chen Yang $\mathbb{D},{ }^{3}$ and \\ Guanchang Xie $\mathbb{B}^{3}$ \\ ${ }^{1}$ School of Civil Engineering, Lanzhou University of Technology, No. 287, Langongping Road, Lanzhou, Gansu 730050, China \\ ${ }^{2}$ Key Laboratory of Disaster Prevention and Mitigation in Civil Engineering of Ministry of Education, \\ Lanzhou University of Technology, No. 287, Langongping Road, Lanzhou, Gansu 730050, China \\ ${ }^{3}$ School of Civil Engineering, Xuchang University, No. 88 Bayi Rd, Xuchang, Henan 461000, China
}

Correspondence should be addressed to Xiaozheng Zhao; zhaoxiaozhenglut@hotmail.com

Received 11 October 2021; Accepted 30 October 2021; Published 22 November 2021

Academic Editor: Meng Jingjing

Copyright @ 2021 Kai Cui et al. This is an open access article distributed under the Creative Commons Attribution License, which permits unrestricted use, distribution, and reproduction in any medium, provided the original work is properly cited.

\begin{abstract}
The degree of damage to heritage structures in arid areas can be particularly serious due to long-term exposure to a harsh arid climate. In this paper, the characteristics of evaporation and cracking of soil taken from heritage structures with different $\mathrm{NaCl}$ concentrations are experimentally investigated by subjecting saturated soil samples taken from the Wang-Jing tower in Weihui City, Henan Province. Making soil sample of water content of $110 \%$ is used to test the rate of evaporation at a constant temperature and humidity, through which the changes in the evaporation rate, water content, fracture development, and fracture fractal dimension are obtained. The results show that, (1) with higher water content, $\mathrm{NaCl}$ can affect the evaporation process by increasing the matrix suction of the soil of the Wang-Jing tower and then affect the cracking process of soil. When $0 \%, 1 \%, 2 \%$, and $4 \% \mathrm{NaCl}$ are added, the residual water content of the samples is $3.15 \%, 4.23 \%, 4.82 \%$, and $5.89 \%$, respectively, which show an obvious trend of increasing water content; (2) the period with a stable fracture fractal dimension of the samples is shortened with an increase in $\mathrm{NaCl}$ concentration, and its maximum fractal dimension is reduced in turn; and (3) at a lower water content, $\mathrm{NaCl}$ crystallizes and precipitates in the pores of the soil, which provide a cementitious effect among the soil particles, thus inhibiting crack development.
\end{abstract}

\section{Introduction}

The rapid economic and large-scale infrastructure developments in China have impacted not only the environment but also historical artifacts. Historical buildings, also known as heritage buildings, remnants, tombs, ruins, and relics (collectively called heritage structures here), are physical markers of civilization that attest to the historical and cultural developments of China. Some heritage structures are unfortunately being demolished due to urbanization, while others face deterioration caused by weather elements such as heat, cold, frost, wind, and rain as well as damage caused by humans such as graffiti. Heritage structures are irreplaceable since they have historical value. Therefore, the preservation of heritage structures is imperative so that they can withstand the test of time. In particular, heritage structures in arid lands, such as in northwestern China, face special challenges due to extreme temperature ranges, wind, and dry desert air, which accelerate the deterioration of ceramic, porcelain, and earthly materials such as clay and adobe bricks, with various degrees of damage [1]. Because of the long-term exposure to such harsh climatic environments, the degree of damage to the heritage structures in arid areas can be particularly serious. As such, many researchers have studied the deterioration of heritage structures in arid lands and found that the deterioration is mainly caused by the degradation of the building materials. The degradation is closely related to the basic properties of the materials, such as their density, particle size, amount of soluble salt and minerals, and mechanical strength [2]. In studying the wetdry cycle of soils, Shen et al. (2017) found that soils with sodium sulfate $\left(\mathrm{Na}_{2} \mathrm{SO}_{4}\right)$ added show $\mathrm{Na}_{2} \mathrm{SO}_{4}$ on the surface 
of the material, while soils with sodium chloride $(\mathrm{NaCl})$ show less $\mathrm{NaCl}$ on the surface [3]. The degree of damage of the material with salt depends on the crystallization process of the minerals. When the initial water content of the soil taken from the heritage structures in arid lands is less than $5 \%$, its strength and durability decrease during the freezethaw cycle, which eventually results in severe loss of strength of the material [4].

In recent years, extreme weather conditions that range from drought to heavy rainfall have resulted in an increase in cracking of exposed soil surfaces, which has led to more research activities that strive to understand soil cracking and treatment, especially in arid lands $[5,6]$. Dry shrinkage cracks are a common phenomenon caused by capillary suction and tensile stresses due to drying [7-9]. It is known that the formation and expansion of cracks and crack networks depend on many internal and external factors. For example, adding biochar to soils can change the evaporation process and therefore change the characteristics of drying and shrinkage cracks of sodium soil. This effectively reduces the disorderly arrangement of surface cracks of soil, which reduces or inhibits soil cracking [10]. Yang et al. (2021b) studied the fractal dimension of surface cracks and the rate of crack growth by adding different amounts of fly ash to soil. They concluded that the shrinkage and evaporation processes in soil are closely related to the properties of the soil, such as the clay content, mineral composition, and internal soil structure [11]. Li et al. (2021) and Yang et al. (2020) studied the development of surface cracks on soil with biomass ash by using image processing technology and the fractal theory. Some scholars found that the addition of biomass ash to soil can effectively prevent the evaporation of water in the soil and soil cracking $[12,13]$. Wang et al. (2021) and Bing et al. (2021) proposed a statistical framework to describe the probability of the distribution of the fractured area as a function of the water content. The effects of maize roots and $\mathrm{NaCl}$ on the changes in the morphology of the fractures in the shrinkage and swelling of soil are determined $[14,15]$. Others found that the presence of salt can effectively inhibit crack development. Tension cracks in soil slopes significantly reduce their stability by allowing deeper and faster infiltration of water into the slopes. The formation of tension cracks depends on the type of soil, the degree of drying of the slope surface, and the availability or lack of water [16-19]. Therefore, previous studies show that adding an additive, such as salt or biochar, to soil can change the characteristics of soil, which is relevant to this study, which involves an arid climate and heritage structures that are constructed of soil.

The alkalization of soils in the arid areas of northwestern China is due to intense rainfall that is short in duration and an arid climate which contributes to a high rate of evaporation, thus causing water and salt migration. On the one hand, water movement in the soil results in salt migration from the top to the bottom and the inside to the outside of the soil layer, which may eventually accumulate and form a salinization zone at the bottom of heritage structures that are made of soil [20]. On the other hand, capillary action results in uneven distribution of salt on the soil surface at the maximum height of the capillary rise in the soil [21], which leads to alkalization of the soil. The deterioration of the heritage structure includes flaking and stripping of the soil surface, erosion, and cracking, which are closely related to water and salt transport in the soil. The deterioration of the soil leads to serious damage to the heritage structures [22, 23]. Shen et al. (2014) studied the salinization process of soil with different concentrations of $\mathrm{NaCl}$ and $\mathrm{Na}_{2} \mathrm{SO}_{4}$ with the use of ultrasonic testing. They found that the speed of the $\mathrm{P}$ wave gradually decreases with an increase in the number of wetting and drying cycles. Also, an increase in salt content accelerates the salinization process [24]. Cui et al. (2019) found that heritage structures have been damaged to various degrees due to the coupling action of freeze-thaw cycles and salt salinization caused by snowfall by monitoring the temperature, water contents, and soluble salt concentration in the soil at three typical heritage structures sites in Northwest China [25].

Many heritage structures in China are built on, in, or with soils. However, with time, they degrade. As these structures have historical importance, it is very important to study the degradation of soils in order to preserve these structures. There are a number of studies conducted on the foundation soil of heritage structures in China. However, there are few studies on the Wang-Jing tower located in Weihui City, Henan Province, China. The Wang-Jing tower has special relevance because it is the largest building constructed of stone without any beams. In this paper, the foundation soil of the Wang-Jing tower is studied to determine the effects of $\mathrm{NaCl}$ on the mechanical properties of the soil. The effects of $\mathrm{NaCl}$ are studied. As such, this addition of $\mathrm{NaCl}$ is expected to change the evaporation rate of the soil, which can be measured by the change in the water contents. Drying of the soil will lead to surface crack development, which is captured by using a camera and processed with image processing software. This will provide a quantitative measure of the effect of $\mathrm{NaCl}$ on surface crack initiation and propagation in the soils.

\section{Materials and Method}

2.1. Materials. The soil used in the experiment was obtained from the foundation of the Wang-Jing tower in Weihui City, which is located on the North China Plain and has a warm continental climate. There is an abundance of water from rainfall and plenty of sunny days in Weihui. Hot and wet summer days result in the wetting and drying cycles of the ground, which promote surface crack development. The walls of the Wang-Jing tower have visible cracks before and after restoration work was done on the tower in 2006; see Figure 1. The cracking of the tower might be caused by the uneven settlement of foundation soil due to the cracking. In order to study the foundation soil, four sampling points were located near the tower. Soil samples were obtained at a depth of 10 to $20 \mathrm{~cm}$ from the ground surface. The soil samples were then air-dried in the laboratory, crushed, and sieved through a $2 \mathrm{~mm}$ sieve; see Figures 2(a)-2(c). The physical and mechanical properties of the soil are shown in Table 1.

2.2. Experimental Method. In the experiment, the soil samples with a particle size less than $2 \mathrm{~mm}$ were divided into four groups: a group without $\mathrm{NaCl}$ was used as the control, 


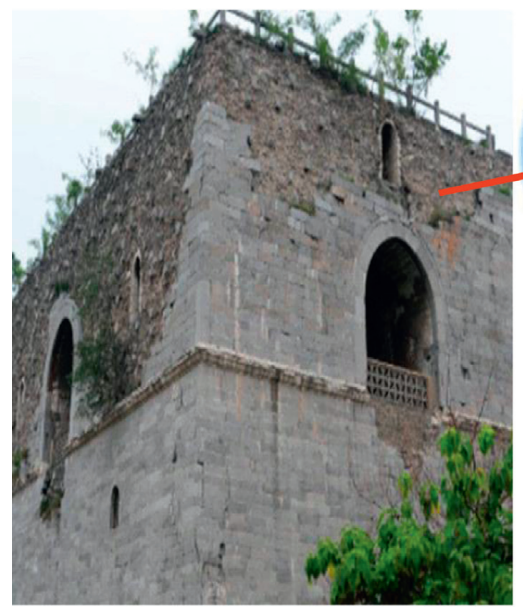

(a)
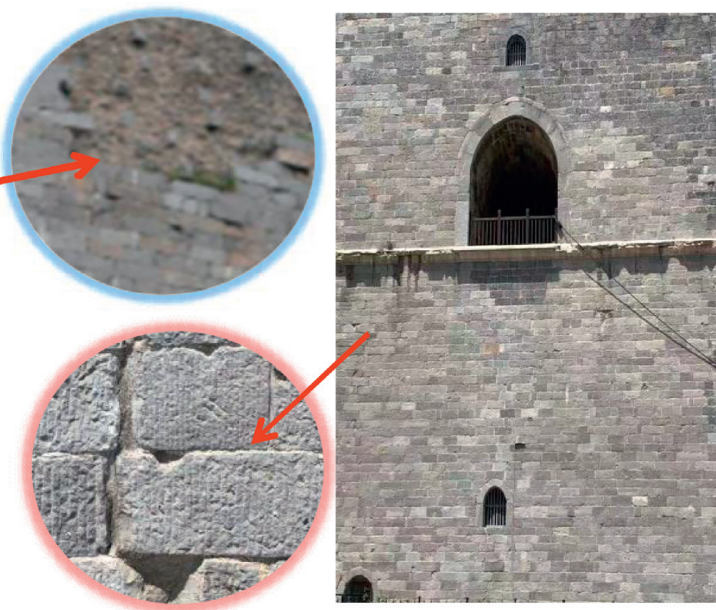

(b)

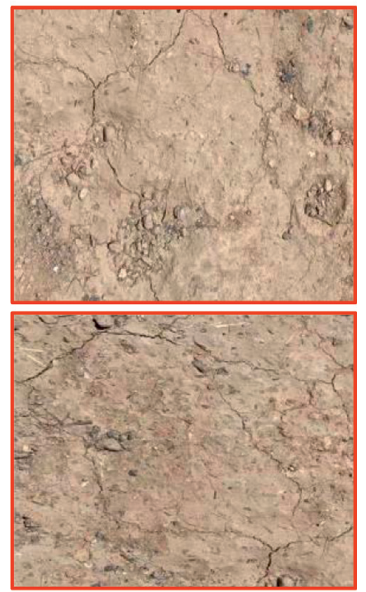

(c)

FIGURE 1: Condition of the Wang-Jing tower and foundation soil. (a) Before the repair. (b) After the repair. (c) Crack phenomenon of foundation soil.

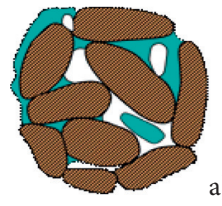

Soil sample

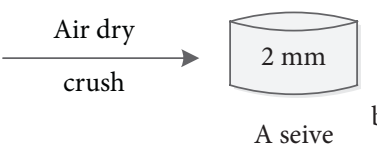

b)

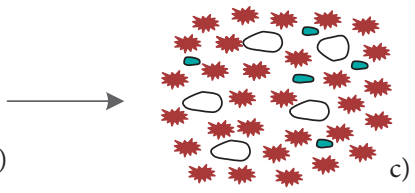

Microsoil particle

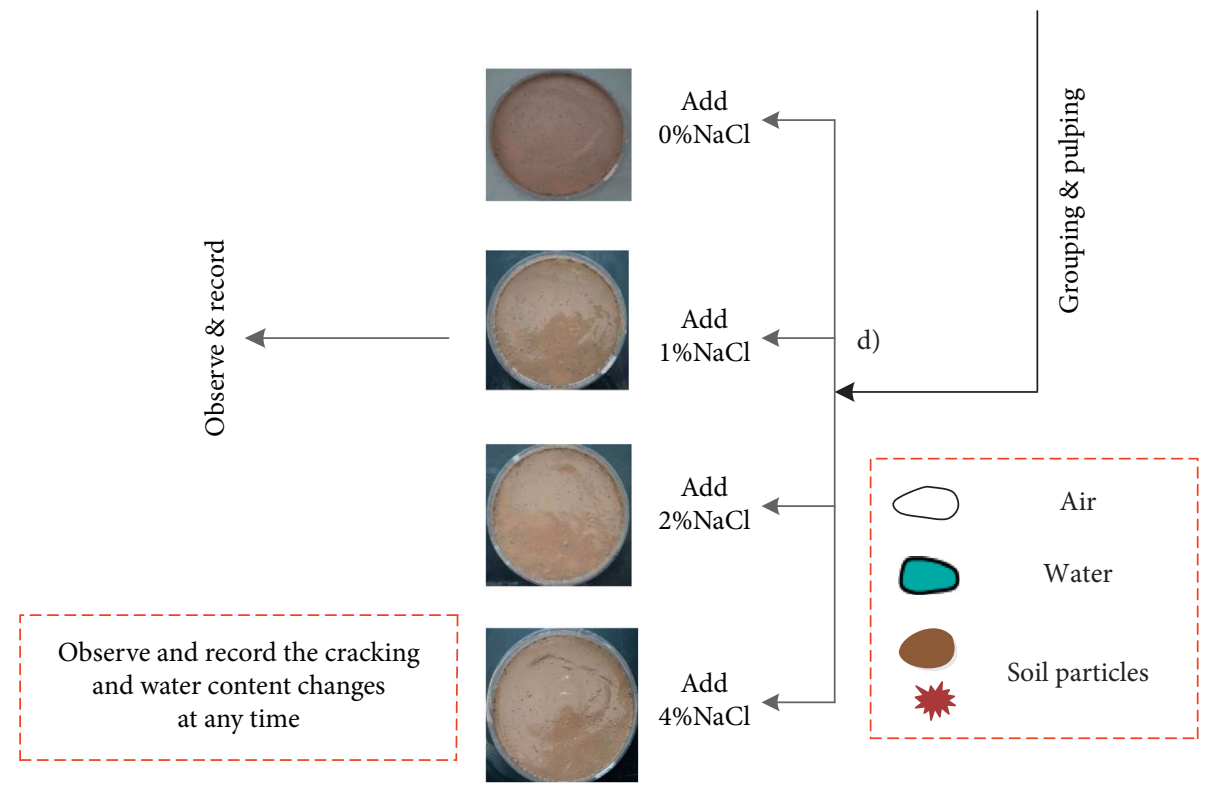

Figure 2: Flowchart of the experimental process.

TABLe 1: Physical and mechanical properties of the soil from the Wang-Jing tower.

\begin{tabular}{|c|c|c|c|c|c|c|c|}
\hline $\begin{array}{l}\text { Density } \rho \\
\left(\mathrm{g} \cdot \mathrm{cm}^{-3}\right)\end{array}$ & $\begin{array}{l}\text { Liquid limit } \\
W_{\mathrm{L}}(\%)\end{array}$ & $\begin{array}{c}\text { Plastic limit } \\
W_{\mathrm{P}}(\%)\end{array}$ & $\begin{array}{l}\text { Plasticity } \\
\text { index } I_{\mathrm{P}}\end{array}$ & $\begin{array}{l}\text { Cohesion c } \\
\quad(\mathrm{kPa})\end{array}$ & $\begin{array}{c}\text { Internal } \\
\text { friction angle } \varphi \\
\left({ }^{\circ}\right)\end{array}$ & $\begin{array}{c}\text { Coefficient of } \\
\text { compressibility a } \\
\left(\mathrm{MPa}^{-1}\right)\end{array}$ & $\begin{array}{c}\text { Compression } \\
\text { modulus } E_{\mathrm{S}}(\mathrm{MPa})\end{array}$ \\
\hline 1.88 & 60.34 & 37.71 & 22.63 & 58.13 & 23.31 & 0.223 & 9.094 \\
\hline
\end{tabular}


and the other three groups had $\mathrm{NaCl}$ concentrations of $1 \%$, $2 \%$, and $4 \%$ of the dry soil mass. Distilled water was added to all of the soil samples to give an initial water content of $110 \%$ as shown in Table 2 . The soils were thoroughly mixed for 30 minutes to produce a homogeneous material. The soils were poured into $25 \mathrm{~cm}$ diameter cylindrical plexiglass containers of $4 \mathrm{~cm}$ in height; see Figure 2(d). Two sets of samples were made for each group for comparison of the test results.

The samples were placed in an environmentally controlled incubator for 10 days under a constant temperature of $25^{\circ} \mathrm{C}$ and humidity of $40 \%$ so that the $\mathrm{NaCl}$ could be completely absorbed in the soil. After 10 days in the incubator, the soil samples were removed and mixed again to ensure that each sample was homogeneous. The samples were placed in a constant temperature drying oven at a temperature of $25^{\circ} \mathrm{C}$ and relative humidity of $40 \%$. Pictures were taken during the drying process to observe the crack development. The water contents were calculated by measuring the changes in the mass of the samples. The tests were terminated when there were no observable changes in the water content.

2.3. Image Processing. With the rapid development of computer imagery, digital image processing technology has been widely used in many fields in science and engineering. In studying the process of fracture development, it is necessary to process digital images quantitatively by calculating various fracture parameters in order to analyze the geometric and morphological characteristics of the fracture network [26-28]. In processing digital images, the first step is to convert the original colored image (Figure 3(a)) to grayscale in order to better observe the cracks (Figure 3(b)). Impurities due to sample defects or image noise are removed in the second step to improve the quality of the image and increase the accuracy of the quantitative fracture analysis (Figure 3(c)). In the third step, the grayscale image is binarized by using the threshold segmentation method to convert the grayscale image into black and white pixels. During the conversion, the target pixels within a certain threshold range are assigned the same color, that is, black or white, so that the contours and boundaries of the fractures are enhanced (Figure 3(d)). Based on the black and white image, the fracture network is enhanced in the fourth step; see Figure 3(e). Finally, the fractal dimensions are calculated for all of the fractures; see Figure 3(f).

2.4. Calculation of Evaporation Rate. During the test, the loss of weight of the samples is due to the evaporation of water. Drying of the soil also results in the development of surface cracks. The evaporation rate $(E)$ is an important indicator of fracture development. At the experimental site, the parallel sample (rectangular shape) was soaked with water and placed in the air together with the electronic balance, whose change of the weight at different times was recorded by a computer. The evaporation rate $(E)$ per unit surface area of the sample can be calculated from the following formula:
TABle 2: Test design of the samples.

\begin{tabular}{lccc}
\hline Sample no. & Parallel sample & $\mathrm{NaCl}(\%)$ & Initial water content (\%) \\
\hline $1-1$ & $1-2$ & 0 & 110 \\
$2-1$ & $2-2$ & $1 \%$ & 110 \\
$3-1$ & $3-2$ & $2 \%$ & 110 \\
$4-1$ & $4-2$ & $4 \%$ & 110 \\
\hline
\end{tabular}

$$
E=\frac{\Delta m}{\left(\Delta t \cdot S_{E}\right)},
$$

where $\Delta m$ is the mass of the evaporated water, $\Delta t$ is the evaporation time, and $S_{E}$ is the surface area of the soil sample.

Fractal dimension can quantitatively characterize the morphological characteristics of fractures, which are an important parameter that can be calculated from the digital images of the fractures. In this study, the box dimension method is used. The box dimension method calculates the factual dimension by covering the entire image with square boxes of dimension $r$. The fractal dimension $D$ can be calculated from the total number of box counts, $N$, as follows:

$$
D=-\lim _{r \longrightarrow 0} \frac{\lg N(r)}{\lg r} .
$$

\section{Laboratory Test Results}

3.1. Effects of Salt Content on the Rate of Evaporation. The initial water content of all of the samples is $110 \%$. The results on the changes in the water content and the rate of evaporation are shown in Figure 4. Figures 4(a) and 4(b) show the changes in water content with time. All four groups of samples with different $\mathrm{NaCl}$ concentrations show a similar trend with time, that is, a gradual decrease in the water content with drying and reducing to stable water content at the end of the drying process. However, there is some fluctuation of the water content for Sample 1, which does not contain $\mathrm{NaCl}$, before reaching the final stable state. The water content of Samples 2, 3, and 4 with $\mathrm{NaCl}$ concentrations of $1 \%, 2 \%$, and $4 \%$, respectively, is smoothly decreased before the final state. In the final stage of drying, the residual water content in the sample with a high $\mathrm{NaCl}$ concentration is significantly higher than that in the sample with lower $\mathrm{NaCl}$ concentrations. The samples with $0 \%, 1 \%$, $2 \%$, and $4 \% \mathrm{NaCl}$ have residual water contents of $3.15 \%$, $4.23 \%, 4.82 \%$, and $5.89 \%$, respectively, which show an obvious trend of increasing water content.

The trend of the rate of evaporation with time for all of the samples with different $\mathrm{NaCl}$ concentrations is basically the same; see Figures 4(c) and 4(d). Based on the evaporation rate with time, the evaporation process can be divided into three stages: the first stage is a constant rate of evaporation, the second stage is a decreasing rate of evaporation, and the final stage is the residual evaporation stage. In the first stage, the soil has excess free water, and surface evaporation is controlled by the relative humidity of the air in the 


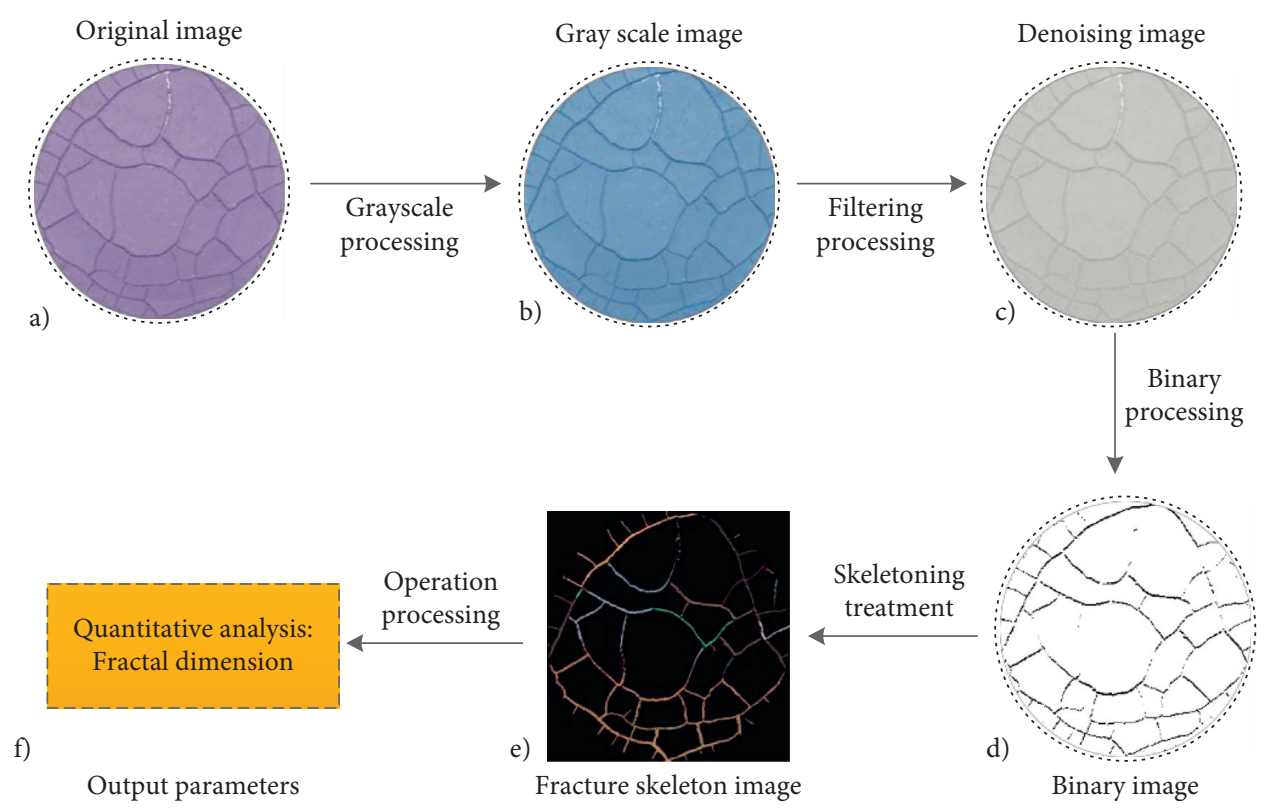

FIGURE 3: Flowchart of processing crack image.

surrounding environment. The evaporation rate is about $0.9 \mathrm{~g} / \mathrm{h}$ and fairly constant with time. In the second stage, when all of the excess surface water has been evaporated, there is an unsaturated flow on the surface of the sample. The rate of evaporation decreases with time due to the reduced permeability of the soil at the surface under unsaturated flow conditions. In the third stage, most of the free water has been evaporated with only water particles that are more tightly bonded to the soil particles remaining. Evaporation has basically ceased, and the residual water content does not change with time. Removal of the remaining water is not only dependent on the relative humidity of the surrounding air but also dependent on the temperature. Increases in temperature will result in more removal of water from the soil.

Based on the experimental results, the trend of the rate of evaporation of the samples with different $\mathrm{NaCl}$ concentrations is basically the same. The residual water content of Samples $1,2,3$, and 4 with $\mathrm{NaCl}$ concentrations of $0 \%, 1 \%$, $2 \%$, and $4 \%$ is $3.15 \%, 4.23 \%, 4.82 \%$, and $5.89 \%$, respectively, after 142 to 167 hours of evaporation. All of the samples have an initial water content of $110 \%$, which is much higher than the residual water content.

3.2. Effect Salt on Cracking of Soil. The distribution of the surface cracks in the soil can be quantitatively described by using the fractal dimension. A larger fractal dimension denotes more irregular and complex surface cracks [29]. Based on the fractal dimension and changes in the water content of the samples, the development of fractures is divided into three stages accordingly; see Figure 5(a). In the first stage, after the first appearance of the surface cracks, the fractal dimension increases linearly with time. With the rapid development of fractures, a network of connecting fractures appears on the surface of the soil. In the second stage, the rate of fracture development decreases with the formation of secondary fracture networks. In the third and final stage, the fracture network remains unchanged, but the fractures continue to develop with depth and width.

The development of the main fractures in the first stage begins at the end of the first stage of evaporation when all of the free surface water has been evaporated. When cracking of the surface begins, a single crack will develop into multiple cracks, which form the main fracture network. The second stage begins when the rate of evaporation starts to decline and evaporation changes to unsaturated flow at the soil surface. While the main fracture continues to develop, multiple secondary fractures perpendicular to the main fracture begin to appear. With the continuous development of the secondary fracture network, the final fracture network divides the sample into different sizes of blocks. The third stage of fracture development begins at the later stage of the second stage of evaporation. In this stage, fracture development of the sample turns into deepening and widening of the fractures until evaporation stops. At this stage, the growths of the fracture network and fracture development basically stop.

For Samples 2, 3, and 4, the development of fractures follows the three stages discussed here. In comparison to these samples with different $\mathrm{NaCl}$ concentrations (Figure 5(a)), there is no obvious trend of the fractal dimensions with $\mathrm{NaCl}$ concentrations in the first stage of fracture development. However, the length of time of the second stage is dependent on the $\mathrm{NaCl}$ concentration. The duration of the second stage for Samples 1, 2, 3, and 4 is $56 \mathrm{~h}$, $52 \mathrm{~h}, 20 \mathrm{~h}$, and $10 \mathrm{~h}$, respectively, which shows a decrease in time with an increase in $\mathrm{NaCl}$ concentration. The results show that the fractal dimension of Sample 1 with $0 \% \mathrm{NaCl}$ is significantly higher than that of the other samples. However, the fractal dimensions of Samples 2, 3, and 4 do not follow a decreasing trend with an increase in $\mathrm{NaCl}$ concentration. In 


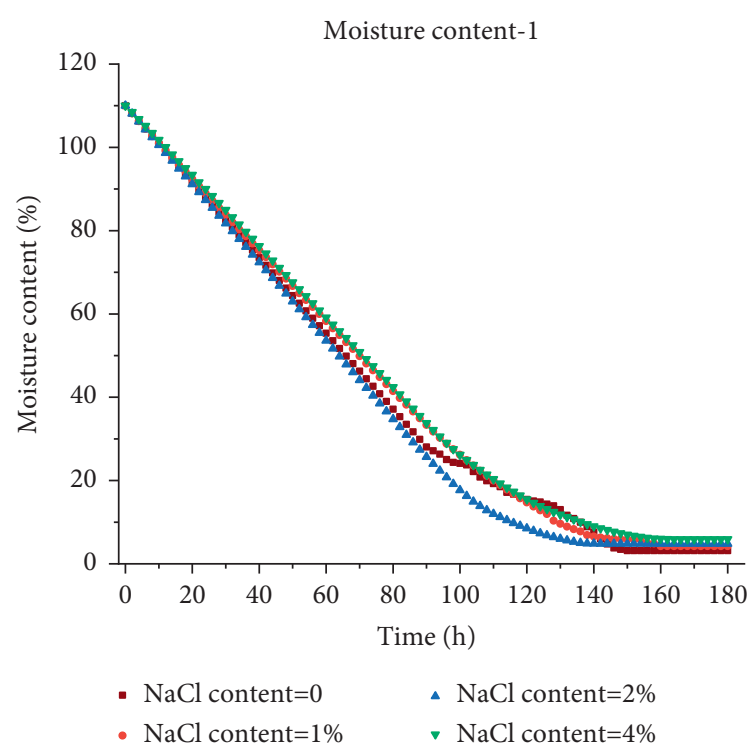

(a)

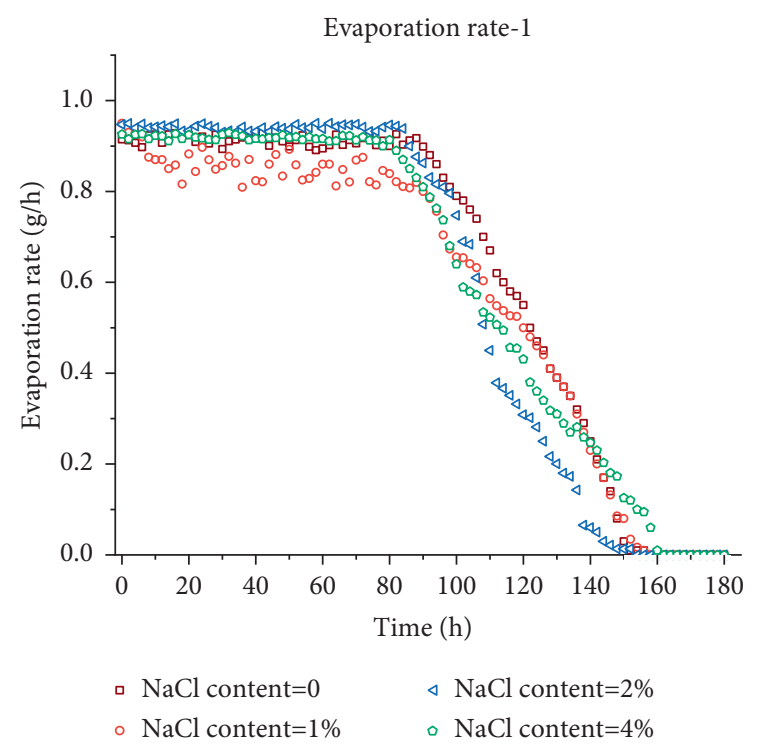

(c)

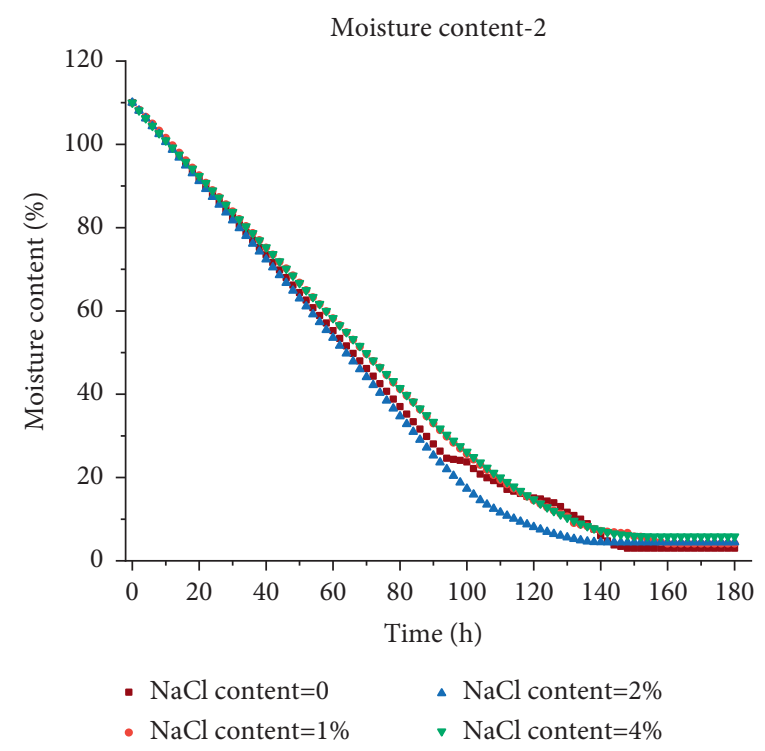

(b)

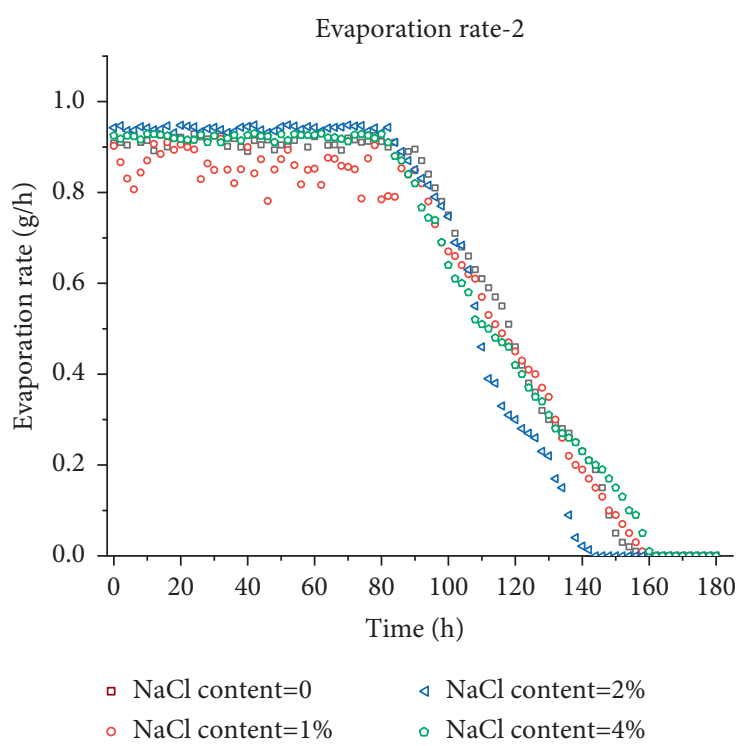

(d)

Figure 4: Rate of evaporation versus time. (a) Water content versus salt concentration. (b) Water content versus salt concentration of the second set of samples. (c) Rate of evaporation of samples with time for different salt concentrations. (d) Evaporation rate of samples with time for different salt concentrations of the second set of samples.

the third stage, the fracture development tends to be stable, and the fracture fractal dimensions reach the maximum values. The maximum fractal dimension decreases with an increase in $\mathrm{NaCl}$ concentration. The maximum fractal dimension of Samples 1, 2, 3, and 4 is $1.78,1.7,1.67$, and 1.62, respectively. The maximum fractal dimension decreases significantly with increases in $\mathrm{NaCl}$ concentrations; see Figure 5(b).

\section{Discussion}

The evaporation rate of the soil samples clearly shows three stages of development, namely, the constant rate of evaporation, decreasing rate of evaporation, and residual evaporation stages; see Figure 4. Evaporation of the sample occurs on the soil surface. The evaporation of water on the surface of the sample is due to the migration of water from the lower part to the sample to the surface. In the first stage of evaporation, the escape of the water molecules on the surface of the sample is replenished by the flow of water and salt to the surface due to capillary action. Since the soil is oversaturated and there is excess free water in the soil, the flow of water from inside the sample to the surface is under a saturated state. Not only is the flow of water relatively constant as there is no significant change in the saturated permeability of the sample, but also the rate of the water flow is higher compared to the unsaturated state. Therefore, the rate of evaporation is constant during this stage. Capillary 


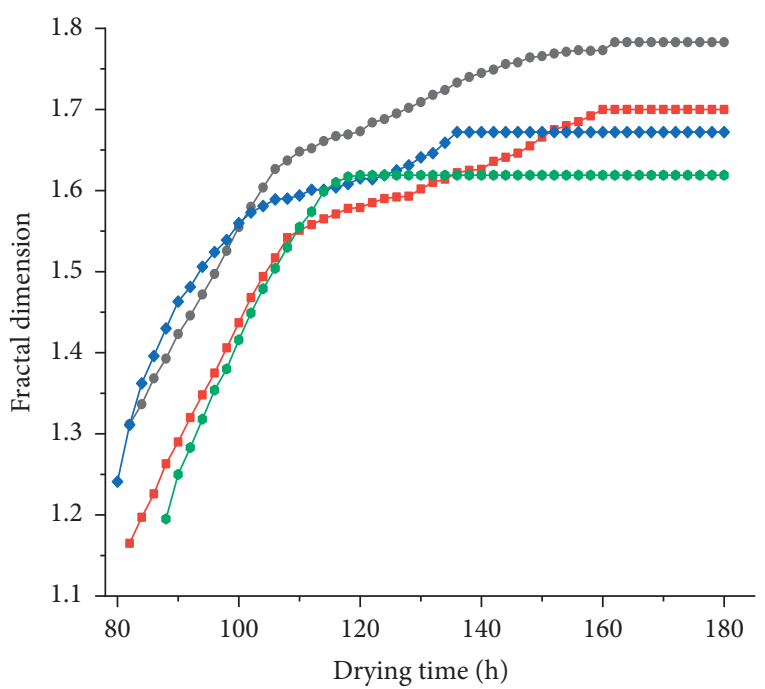

$\longrightarrow \mathrm{NaCl}$ content $=0 \quad \rightarrow \mathrm{NaCl}$ content $=2 \%$
$\longrightarrow \mathrm{NaCl}$ content $=1 \% \quad \rightarrow \mathrm{NaCl}$ content $=4 \%$

(a)

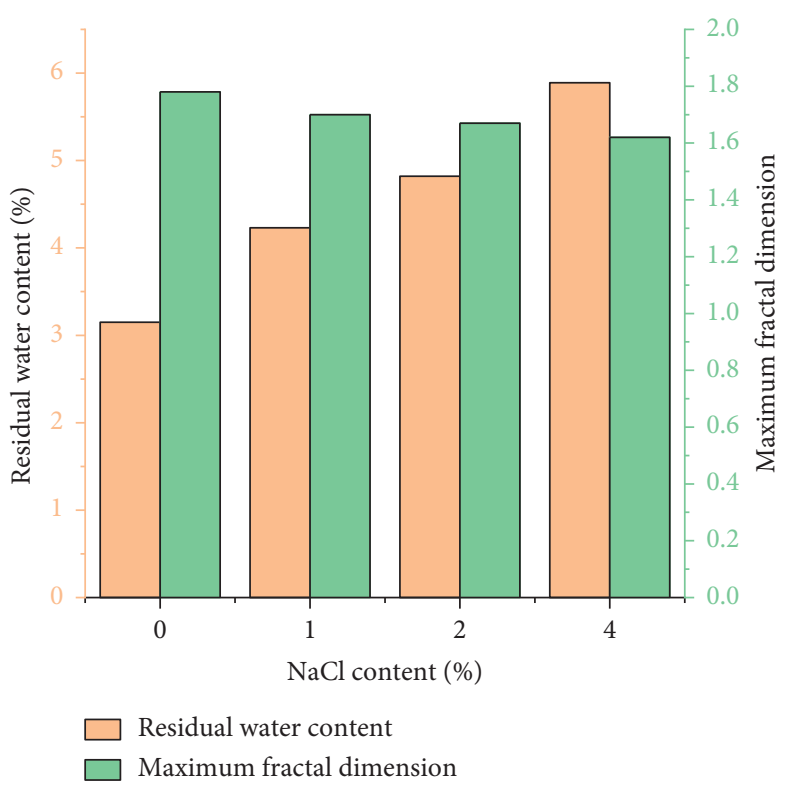

(b)

Figure 5: Fractal dimension with different $\mathrm{NaCl}$ concentrations. (a) Fractal dimension with time. (b) Residual water content and maximum fractal dimension versus $\mathrm{NaCl}$ concentration.

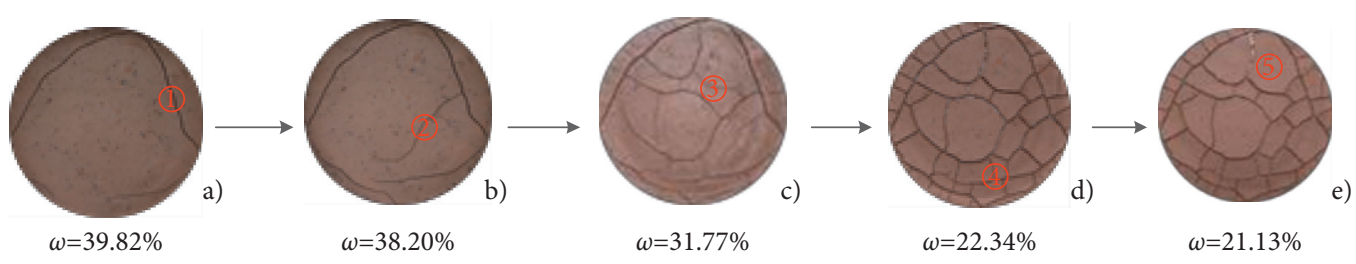

Figure 6: Crack development of Sample 1 during drying. Figure 6 mainly expresses the evolution process of fractures. It is observed that the main fracture appears at first, and then a secondary fracture appears in the direction perpendicular to the main fracture, continues, and finally evolves into the network fracture shape in Figure 6(e). (a) $w=39.82 \%$. (b) $w=38.20 \%$. (c) $w=31.77 \%$. (d) $w=22.34 \%$. (e) $w=21.13 \%$.

water is the free water in the soil, which is found when the water content of the soil is higher than its plastic limit [30]. With further evaporation, the water content of the sample approaches its plastic limit, the capillarity action is reduced or even disappears, and the sample begins to crack. Evaporation enters the second stage. At this time, cracking results in an increase of the surface area for evaporation and a shortening of the migration path of capillary water, which increases evaporation. However, the increase in matrix suction when the soil becomes unsaturated makes evaporation more difficult. The result is a decrease in the evaporation rate. In the third stage, evaporation stops with an increase in the matrix suction and the disappearance of capillarity.

Evaporation causes a decrease in the water content with time, and the soil changes from a more fluid state to a solid state. With decreases in the water content and increases in the matrix suction, surface cracks develop due to increases in the tensile stress. The number, length, width, and depth of the cracks gradually increase with evaporation, and crack development becomes more intense. For example, the crack development process of Sample 2 with $1 \% \mathrm{NaCl}$ is shown in
Figure 6. After $81 \mathrm{~h}$ of drying, the water content of the sample reaches $39.82 \%$, which is close to the plastic limit of the soil sample (Table 1), when cracking began. At this time, the main crack (1) appears as shown in Figure 6(a); when evaporation continues, the water content of the sample continues to decline, and secondary fractures, (2) and (3), begin to develop in the direction perpendicular to the main fracture (1); see Figures 6(b) and 6(c). Finally, a network of fractures is formed; see Figure 6(d). As evaporation continues, the length and width of the cracks continue to increase in the area (5) in Figure 6(e) until evaporation stops. After that, there are no more changes in the water content, and the development of the fractures ceases.

In fracture development, the tensile force and tensile strength of the material govern the initial crack development process. During evaporation, a decrease in the water content results in capillary action in the pores of the soil and the development of tensile stress due to matrix suction. When the tensile stress exceeds the tensile strength of the soil, cracking occurs [31]. Because of the development of a gradient in the water content from the surface to the middle of the soil or between different soil layers, cracks first develop 
on the soil surface, which has the lowest water content. Stress concentration occurs at the tip of the crack, which leads to crack propagation, expansion, extension, and widening until a stable crack network is formed [32]. With the continuous reduction in water content, crack development will continue until a stable stress configuration is achieved when the fracture network is fully developed.

Adding $\mathrm{NaCl}$ to the soil has different effects on the capillarity and evaporation with surface crack development in the soil. With increases in salt concentrations and water content, the effective stress in the soil is increased with higher matrix suction and tensile stresses. This results in different initial cracking times. At lower water content, $\mathrm{NaCl}$ crystallizes and precipitates in the pores of the soil, which provide a cementitious effect among the soil particles, thus inhibiting crack development [33]. In short, evaporation makes the water content of soil lower than the plastic limit, resulting in soil cracking. In turn, soil cracking further intensifies evaporation. This process runs continuously. After the evaporation stops, the fracture shape gradually tends to be stable.

\section{Conclusions}

Many studies have shown that adding $\mathrm{NaCl}$ to soil can change the evaporation rate of water. In this study, different amounts of $\mathrm{NaCl}$ have been added to soil to determine the effects of salt on the rate of evaporation. The evaporation process can be divided into three stages: the initial stage with a constant rate of evaporation, the second stage with a declining rate of evaporation, and the final residual evaporation stage. The effect of $\mathrm{NaCl}$ on the rate of evaporation is not significant. With increases in salt content, the average rate of evaporation decreases. The final residual water content of the samples with the same initial water content is $3.15 \%, 4.23 \%, 4.82 \%$, and $5.89 \%$ for samples with $0 \%, 1 \%$, $2 \%$, and $4 \% \mathrm{NaCl}$, respectively. The changes in the evaporation rate of the soils are mainly caused by the coupling effects of the physical and mechanical properties of the soil, including capillary action, water and salt migration, matrix suction, and crack development.

Evaporation plays an important role in the cracking and crack development of soils. Evaporation causes a decrease in the water content of the soil until the soil reaches the plastic limit when cracking occurs. Crack development continues until the end of the evaporation process. Fractal dimension is an important parameter to characterize the development and distribution of surface cracks. With different $\mathrm{NaCl}$ concentrations, the time for the initial cracking is different, but the crack development process shows three obvious stages. With increases in the $\mathrm{NaCl}$ concentration, there is no significant change in the fractal dimension in the first and second stages of evaporation. However, in the third stage, the fractal dimension decreases with increases in $\mathrm{NaCl}$ concentration. The maximum fractal dimension of the soil samples is $1.78,1.7,1.67$, and 1.62 for Samples 1, 2, 3, and 4, respectively. The maximum fractal dimension decreases with increases in $\mathrm{NaCl}$ concentration. The findings are helpful for ensuring the sustainability and long-term stability of the
Wang-Jing tower as well as other heritage structures in northwestern China that are threatened by the same arid climate with similar soil foundations.

\section{Data Availability}

The datasets generated during the current study are available from the corresponding author on reasonable request.

\section{Conflicts of Interest}

No conflicts of interest exist in the submission of this manuscript, and the manuscript is approved by all authors for publication.

\section{Acknowledgments}

The authors would like to acknowledge the financial support from the National Natural Science Foundation of China under Grants nos. 52068050 and 41562015 and the Henan College Students' Innovation And Entrepreneurship Training Program under Grant no. S202110480034.

\section{References}

[1] M. Dong, H. Hu, Q. Guo, X. Gong, R. Azzam, and M. Kong, "Correlation of environmental parameters and the water saturation induced deterioration of earthen archaeological sites: the case of world heritage liangzhu city, China," Heritage, vol. 4, no. 1, pp. 387-400, 2021.

[2] M. Shao, L. Li, S. Wang, E. Wang, and Z. Li, "Deterioration mechanisms of building materials of Jiaohe ruins in China," Journal of Cultural Heritage, vol. 14, no. 1, pp. 38-44, 2013.

[3] Y. X. Shen, W. W. Chen, J. Kuang, and W. F. Du, "Effect of salts on earthen materials deterioration after humidity cycling," Journal of Central South University, vol. 24, no. 4, pp. 796-806, 2017.

[4] T. Zhao, H. Zhang, G. Yan, L. Ping, and H. Y. Zhang, "Geotechnical approach to earthen architecture durability by cyclic freeze and thaw test," Electronic Journal of Geotechnical Engineering, vol. 17 C, pp. 263-276, 2012.

[5] C. L. Liu, C. S. Tang, K. Q. Sun, H. Li, S. K. Xu, and T. Leng, "Review on the mechanism and theoretical model of desiccation cracking in clay soil," Journal of Engineering Geology, vol. 26, no. 2, pp. 296-308, 2018.

[6] X. P. Gong, C. S. Tang, B. Shi et al., "Evolution of soil microstructure during drying and wetting," Journal of Engineering Geology, vol. 27, no. 4, pp. 775-793, 2019.

[7] K. F. DeCarlo and N. Shokri, "Effects of substrate on cracking patterns and dynamics in desiccating clay layers," Water Resources Research, vol. 50, no. 4, pp. 3039-3051, 2014.

[8] R. D. Stewart, D. E. Rupp, M. R. N. Abou, and J. S. Selker, "A unified model for soil shrinkage, subsidence, and cracking," Vadose Zone Journal, vol. 15, no. 15, 2016.

[9] G. Zhao, K. B. Ren, and Q. W. Ma, "Research on collapse failure process and mechanism of earthen sites under the action of capillary water," Applied Mechanics and Materials, vol. 438-439, pp. 1226-1231, 2013.

[10] B. Yang, D. Li, S. Yuan, and L. Jin, "Role of biochar from corn straw in influencing crack propagation and evaporation in sodic soils," Catena, vol. 204, Article ID 105457, 2021 .

[11] B. Yang, J. Liu, X. Zhao, and S. Zheng, "Evaporation and cracked soda soil improved by fly ash from recycled 
materials," Land Degradation \& Development, vol. 32, no. 9, pp. 2823-2832, 2021b.

[12] D. Li, B. Yang, Z. Gao, and L. Sun, "The effects of biomass ash on soil evaporation and cracking," Arabian Journal of Geosciences, vol. 14, no. 10, pp. 1-11, 2021.

[13] B. Yang, K. Xu, and Z. Zhang, "Mitigating evaporation and desiccation cracks in soil with the sustainable material biochar," Soil Science Society of America Journal, vol. 84, no. 2, pp. 461-471, 2020.

[14] C. Wang, G. Feng, Z. Zhang, M. Huang, W. Qi, and L. Ma, "Geometrical and statistical analysis of dynamic crack morphology in shrink-swell soils with addition of maize roots or salinity ( $\mathrm{NaCl})$," Soil and Tillage Research, vol. 212, Article ID 105057, 2021.

[15] B. X. Yuan, Z. H. Li, Y. M. Chen et al., "Mechanical and microstructural properties of recycling granite residual soil reinforced with glass fiber and liquid-modified polyvinyl alcohol polymer," Chemosphere, vol. 286, Article ID 131652, 2021.

[16] Z. G. Luo, C. Xu, Z. B. Yan, and S. J. Wang, "Study on fracture measurement of soils and quantitative analysis of the cracking process," Chinese Journal of Underground Space and Engineering, vol. 17, no. 01, pp. 126-134, 2021a.

[17] J. M. Zhang, Y. Luo, Z. Zhou, L. Chong, C. Victor, and Y. F. Zhang, "Effects of preferential flow induced by desiccation cracks on slope stability," Engineering Geology, vol. 288, Article ID 106164, 2021.

[18] B. X. Yuan, Z. H. Li, Z. L. Su, Q. Z. Luo, M. J. Chen, and Z. Q. Zhao, "Sensitivity of multistage fill slope based on finite element model," Advances in Civil Engineering, vol. 2021, Article ID 6622936, 13 pages, 2021.

[19] B. Yuan, Z. Li, Z. Zhao, H. Ni, Z. Su, and Z. Li, "Experimental study of displacement field of layered soils surrounding laterally loaded pile based on transparent soil," Journal of Soils and Sediments, vol. 21, no. 9, pp. 3072-3083, 2021.

[20] K. Cui, W. W. Chen, and X. D. Wang, "Study of microscopic mechanism of effect of aeolian erosion ullage at salinization belt on earthen ruins in arid region," Rock and Soil Mechanics, vol. 33, no. 04, pp. 1167-1172, 2012, https://www.google.co.in/ books/edition/Rock_and_Soil_Mechanics/xuT5xiVG_bwC?hl $=\mathrm{en} \& \mathrm{gbpv}=0$ in Chinese.

[21] Y. Zhang, W. M. Ye, B. Chen, Y. G. Chen, and B. Ye, "Desiccation of $\mathrm{NaCl}$-contaminated soil of earthen heritages in the Site of Yar City, northwest China," Applied Clay Science, vol. 124-125, pp. 1-10, 2016.

[22] K. Cui, W. W. Chen, L. Han, X. D. Wang, and W. F. Han, "Effects of salinized deterioration and aeolian ullage on soils in undercutting area of earthen ruins in arid region," Chinese Journal of Geotechnical Engineering, vol. 33, no. 9, pp. 14121418, 2011.

[23] B. Yang, S. Yuan, Y. Liang, and J. Liu, "Investigation of overburden failure characteristics due to combined mining: case study, Henan Province, China," Environmental Earth Sciences, vol. 80, no. 4, p. 143, 2021.

[24] Y. X. Shen, W. W. Chen, J. Kuang, and W. F. Du, "Experimental study on salt deterioration of salt contaminated earthen materials under dry-wet cycles," in Proceedings of the The 3rd International Conference on Salt Weathering of Architecture and Stone, Brussels, Belgium, October 2014.

[25] K. Cui, G. Wu, Y. Du, X. An, and Z. Wang, "The coupling effects of freeze-thaw cycles and salinization due to snowfall on the rammed earth used in historical freeze-thaw cycles relics in northwest China," Cold Regions Science and Technology, vol. 160, pp. 288-299, 2019, in Chinese.
[26] N. An, C.-S. Tang, S. K. Xu, X. P. Gong, B. Shi, and H. I. Inyang, "Effects of soil characteristics on moisture evaporation," Engineering Geology, vol. 239, pp. 126-135, 2018.

[27] H. Zeng, C. S. Tang, Q. Cheng, C. Zhu, L. Y. Yin, and B. Shi, "Drought-induced soil desiccation cracking behavior with consideration of basal friction and layer thickness," Water Resources Research, vol. 56, no. 7, Article ID e2019WR026948, 2020.

[28] H. Shin and J. C. Santamarina, "Desiccation cracks in saturated fine-grained soils: particle-level phenomena and effective-stress analysis," Géotechnique, vol. 61, no. 11, pp. 961-972, 2011.

[29] K. Q. Sun, C. S. Tang, P. Wang, D. Y. Wang, Z. G. Chen, and S. K. Xu, "Effect of salt content on desiccation cracking behavior of soil," Journal of Engineering Geology, vol. 23, no. s1, pp. 77-83, 2015.

[30] X. Y. Gao, Soil Mechanics, pp. 50-53, Peking University Press, Beijing, China, 2010.

[31] J. D. Liu, C. S. Tang, H. Zeng, and B. Shi, "Evolution of soil desiccation cracking behavior under drying-wetting cycles," Rock and Soil Mechanics, vol. 42, no. 10, pp. 2763-2772, 2021.

[32] Z. G. Luo, S. J. Wang, J. W. Zhang, and Z. B. Yang, "Thickness effect on crack evolution of expansive soil," Chinese Journal of Geotechnical Engineering, vol. 42, no. 10, pp. 1922-1930, 2020.

[33] Y. Luo, J. M. Zhang, Z. Zhou, Z. J. Shen, L. Chong, and C. Victor, "Investigation and prediction of water infiltration process in cracked soils based on a full-scale model test," Geoderma, vol. 400, Article ID 115111, 2021b. 